\title{
A simple method of detecting abnormal retinal correspondence
}

\author{
ALAN PORTER \\ From the Eye Clinic, Addenbrooke's Hospital, Cambridge
}

SUMMARY A method is described of determining the state of retinal correspondence by means of an ordinary streak retinoscope used to produce a modified after-image test.

The demonstration of the state of retinal correspondence in a squinting child is a procedure usually left to the orthoptic department in eye clinics in Great Britain. Many different techniques of detecting abnormal retinal correspondence have been developed, the majority requiring complicated and expensive equipment. Probably the most commonly used method is that with the major amblyoscope or one of the variations of the after-image test. One of the latest methods is fixation fundus photography developed by Lang and Wurth (1970), in which they photographed the shadow of a fixation target on the retinae of both eyes. There must be few orthoptic departments with such sophisticated equipment, and, as some ophthalmologists have to work without the benefit of even a simple orthoptic clinic, there exists a need for a quick and easy method of detecting abnormal retinal correspondence without recourse to expensive apparatus or skilled technicians.

Recently I have been trying a very simple technique requiring only the use of an instrument that is readily available in virtually every eye clinic and ophthalmologist's consulting room and which, in this instance, requires very little skill on the part of the user. The instrument is the streak retinoscope, and the method is an adaptation of the after-image test first described by Hering so long ago as 1868 (Hering, 1868).

\section{Methods}

The after-image test apparatus, as modified first by Tschermak (1899) and later by Bielschowsky (1938), consisted of a linear light filament inside a glass tube which was fitted with a central metal band around which the tube could be revolved. With the light filament in the vertical position the patient would

Address for reprints: Dr Alan Porter, Scarborough Hospital, Scalby Road, Scarborough, North Yorkshire fixate the central band with 1 eye for about 10 seconds, the other eye being covered. The filament would then be swivelled into a horizontal position and be fixed by the second eye, the first now being covered. This process would imprint an after-image across the maculae of both eyes. After exposure of each eye the filament is switched off and the patient's attention is directed to these images. In a bright room the patient can see dark negative after-images by looking at a plain wall; or in a darkened room, or by closing his eyes, he can see orange-red positive after-images.

\section{Results}

If retinal correspondence is normal the after-images form a perfect cross (Fig. 1a) irrespective of the position of the eyes relative to each other. In cases

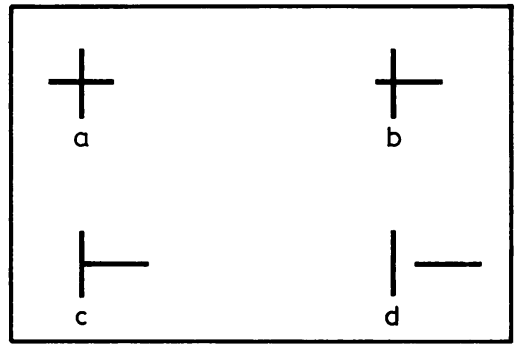

Fig. 1 Varieties of after-image

of abnormal retinal correspondence the crosses will appear eccentric, or even with their limbs completely separated (Figs. $1 b, c, d$ ).

My method of producing the after-images is by using the ordinary streak retinoscope held very close to the patient's eye and asking him to gaze steadily at the light filament. It is important to hold the instrument very still and so it is helpful if its 
upper end can be rested against the patient's brow. The right eye is exposed to the vertical filament and then the left eye to the horizontal filament, each for a count of 10. It is useful to have a few of the possible combinations of the images drawn on a piece of paper and to ask the patient to point to the one most closely resembling the after-images he sees.

\section{Discussion}

The method is successful even in young children and certainly reliable in those capable of co-operating in the Sheridan-Gardner visual acuity test. Any after-image that is not a perfect cross demonstrates the presence of abnormal retinal correspondence.

This method does not, of course, purport to replace a more thorough orthoptic examination, but it does give the busy ophthalmologist a quick and easy way of detecting abnormal retinal correspondence at the time of first examination and with the equipment he already has immediately to hand.

\section{References}

Bielschowsky, A. (1938). Lecture on motor anomalies. American Journal of Ophthalmology, 21, 843-854, 1129 1136, 1219-1229, 1329-1342.

Hering, E. (1868). Die Lehre vom binokularen Sehen. Leipzig. Lang, J., and Würth, A. (1970). Photographic representation of anomalous retinal correspondence. Ophthalmic Research, 1, 88-93.

Tschermak, A. (1899). Ueber anomale Sehrichtungsgemeinschaft der Netzhäute bei einem Schielenden. Albrecht von Graefes Archiv für Ophthalmologie, 47, 508-550. 